\title{
Quality of Publicly Available Physical Activity Apps: Review and Content Analysis
}

Paulina Bondaronek ${ }^{1}$, BSc, MSc, MBPsS; Ghadah Alkhaldi ${ }^{2}$, MPH, PhD; April Slee ${ }^{3}$, MSc; Fiona L Hamilton ${ }^{1}$, MBBS, PhD, FFPH, MRCGP; Elizabeth Murray ${ }^{1}$, PhD, FRCGP, FRCP (Edin)

\footnotetext{
${ }_{1}$ eHealth Unit, Research Department of Primary Care and Population Health, University College London, London, United Kingdom

${ }^{2}$ Community Health Sciences Department, College of Applied Medical Sciences, King Saud University, Riyadh, Saudi Arabia

${ }^{3}$ Research Department of Primary Care and Population Health, University College London, London, United Kingdom
}

\section{Corresponding Author:}

Paulina Bondaronek, BSc, MSc, MBPsS

eHealth Unit

Research Department of Primary Care and Population Health

University College London

Upper 3rd Floor, Royal Free Hospital

Rowland Hill Street

London, NW3 2PF

United Kingdom

Phone: 44203002878

Email: p.bondaronek@ucl.ac.uk

\section{Abstract}

Background: Within the new digital health landscape, the rise of health apps creates novel prospects for health promotion. The market is saturated with apps that aim to increase physical activity (PA). Despite the wide distribution and popularity of PA apps, there are limited data on their effectiveness, user experience, and safety of personal data.

Objective: The purpose of this review and content analysis was to evaluate the quality of the most popular PA apps on the market using health care quality indicators.

Methods: The top-ranked 400 free and paid apps from iTunes and Google Play stores were screened. Apps were included if the primary behavior targeted was PA, targeted users were adults, and the apps had stand-alone functionality. The apps were downloaded on mobile phones and assessed by 2 reviewers against the following quality assessment criteria: (1) users' data privacy and security, (2) presence of behavior change techniques (BCTs) and quality of the development and evaluation processes, and (3) user ratings and usability.

Results: Out of 400 apps, 156 met the inclusion criteria, of which 65 apps were randomly selected to be downloaded and assessed. Almost 30\% apps (19/65) did not have privacy policy. Every app contained at least one BCT, with an average number of 7 and a maximum of 13 BCTs. All but one app had commercial affiliation, 12 consulted an expert, and none reported involving users in the app development. Only 12 of 65 apps had a peer-reviewed study connected to the app. User ratings were high, with only a quarter of the ratings falling below 4 stars. The median usability score was excellent -86.3 out of 100 .

Conclusions: Despite the popularity of PA apps available on the commercial market, there were substantial shortcomings in the areas of data safety and likelihood of effectiveness of the apps assessed. The limited quality of the apps may represent a missed opportunity for PA promotion.

(JMIR Mhealth Uhealth 2018;6(3):e53) doi: 10.2196/mhealth.9069

\section{KEYWORDS}

exercise; health behavior; mobile applications; health promotion; mHealth; eHealth review 


\section{Introduction}

\section{Background}

Physical inactivity is an established independent risk factor for a range of serious health conditions including cardiovascular disease, diabetes mellitus, and cancer [1-3]. Physical activity (PA) is also associated with improved mental health [4,5]. The World Health Organization recommends $150 \mathrm{~min}$ of moderate or 75 min of vigorous intensity PA per week, yet $31.1 \%$ of adults globally fail to achieve this [6]. Behavior change interventions aiming to increase PA tend to have small to moderate effects, with sustainability of intervention effects not well established [7].

Within the new digital health care landscape, the rise of apps creates novel prospects for prevention opportunities and disease management [8]. Mobile health (mHealth) apps, as opposed to traditional face-to-face interventions, are more accessible [9] and provide a range of technology-enhanced features such as accelerometers, visualizations, tailored feedback, and reminders. In addition, recent data show that mobile phone access is now as high among ethnic minority groups in higher income countries as in the rest of the population [10], and the use of mobile phones is increasing steadily in older populations [11], thereby decreasing concerns about the effect of the digital divide on health inequalities. Hence, behavior change interventions delivered using mHealth apps could have the potential to reach a large proportion of the population, thus increasing the public health impact of their small effects [12].

The mHealth app industry has doubled in the last 2 years, with around 165,000 health apps available in the major app stores in 2016 [13]; many of them aiming to increase PA levels. Despite the wide distribution and popularity of health apps, many of them have been rapidly developed [14], and there is lack of evidence of their efficacy. For example, a meta-analysis published by Direito et al [15] found only 7 randomized controlled trials (RCTs) evaluating app intervention for PA and sedentary behavior. It is clearly not feasible for all PA apps to be evaluated by rigorous RCTs, and therefore, alternative methods of evaluating apps are needed. One way of assessing the likely effectiveness of apps is to assess the degree to which they use behavior change theory and adhere to PA guidelines. This research suggests that most PA apps only include a limited number of behavior change techniques (BCTs) [16-18], and they often fail to adhere to PA guidelines [19].

However, quality is about more than effectiveness, although there has been considerable debate about how exactly app quality should be defined, with a variety of frameworks available. Recent reviews by BinDhim et al [14] and Bardus et al [20] categorized and evaluated the methods used for quality assessment of apps. Both studies found a considerable variability in methods and measures used to review the quality of health apps. The approaches used to conceptualize and measure quality varied substantially, and the studies tended to focus on either the design quality or on the presence of evidence-based content but not both [20]. The authors called for more research to assess the quality of both design and content of health apps.
Health apps have the potential to be an important health care tool [21]; hence, health care quality indicators were considered appropriate to apply when assessing the quality of the apps. The concept of quality in health care is complex and multifaceted [22]. Maxwell [23] proposed six dimension of health care quality: accessibility (ease of access to all patient groups), relevance to the need of the community, effectiveness, equity (fairness in the distribution), acceptability, efficiency, and economy (desired health outcomes at the lowest cost). On the other hand, Donabedian [24] proposed a different categorization and argued for three crucial elements that pertain to the quality of health care: structure (facilities and health care professionals available), process (actions by which health care is provided), and outcomes (the results of the actions).

The dimensions of quality proposed by Maxwell and Donabedian were developed before the existence of mobile phones and apps and are perhaps more applicable to health care services provided at the point of need, that is, face-to-face. Potential new health care tools apps need a more concise approach, one that High quality care for all: NHS Next Stage Review Final Report [25] appears to provide. This report outlined the 10-year vision for the National Health Service (NHS) with strategies to improve the quality of care. In this report, high-quality health care was defined as being (1) safe, (2) effective, and (3) providing the most positive experience possible. These quality indicators are simple yet comprehensive and sufficiently flexible to apply to potential new health care tools such as PA apps.

\section{Objective}

In this study, we focused on the most popular apps, which we defined as being in the top rankings of the two major app stores. What constitutes the algorithm that determines the app ranking is unknown. However, variables that indicate popularity such as user ratings, volume of ratings and reviews, download and install counts, usage, and uninstalls are likely to contribute to the ranking in the app stores [26]. In addition, potential users are more likely to focus on the top results and rarely examine the search results thoroughly [27]. This method of defining popularity has been used in other studies assessing apps [28-30], and it was selected to gain a representative sample of apps that are most likely to be used and to simulate the user experience of browsing the store to select a health app.

The aim of this study was to assess the quality of publicly available PA apps. Specific objectives were to assess the safety, effectiveness, and provision of the most positive experience in the most popular PA apps.

\section{Methods}

\section{Study Design}

This study is a review and a content analysis of the most popular, publicly available PA apps on the market. Quality and Risk of Bias Checklist for Studies That Review Smartphone Applications was used to ensure that methods for apps' review are adequately described [14]. 
Textbox 1. Inclusion criteria.

\author{
Apps were included if \\ - Their main goal was to increase physical activity \\ - They were targeted at healthy adults \\ - They had stand-alone functionality
}

Textbox 2. Exclusion criteria.
Apps were excluded if
- The app focused on multiple behaviors, as it would have been difficult to isolate the content pertaining to physical activity
- The target population was patients with a specific health condition, as these users were likely to have different needs to healthy adults
- They were sold as part of a pack ("bundle"), as it would not have been possible to assess the popularity of the individual apps in this bundle

\section{Sample Identification}

A sample of top-ranked $400 \mathrm{PA}$ apps was obtained from the UK's versions of the iTunes and Google Play stores on October 17, 2016. As previous research indicated an association between price and inclusion of BCTs $[18,31,32]$, both free and paid apps were included in the study. Apps' titles and descriptions from the "Health and Fitness" category in both stores (100 iTunes free +100 iTunes paid +100 Google Play free +100 Google Play paid) were screened against the inclusion and exclusion criteria. (Textboxes 1 and 2)

\section{Sample Assessment}

From the apps identified, 65 were randomly selected for the assessment using the random number generator function in Excel (Microsoft). As the largest subset of health apps on the market (30\%) [13] target PA, it was expected that a high number of apps would fulfil the inclusion criteria. We were undertaking a parallel study to assess the association between quality indicators and user rating, and the choice of $n=65$ was based on the power calculation for that parallel study.

The apps were downloaded onto an iPhone SE and 6 (running iPhone operating system [iOS, Apple Inc] 10.2.1 and 9.3.4 software, respectively) and Android Samsung Galaxy S6 and J5 (running 6.0.1 or 5.1.1 software, respectively) and assessed using a pro forma evaluation. Each app was left running in the background for 2 days for the assessors to explore any reminders or notifications. If two apps were identified as duplicates and there appeared to be consistency of design and content between both operating systems, the apps were assessed on an iPhone only. The sample identification and assessment was conducted independently by two reviewers (PB and GA), and any discrepancies were resolved through discussion.

\section{Data Extraction}

\section{Descriptive Data}

We extracted the following descriptive data from both app stores: app's name, brief description, type of PA targeted (eg, running, walking, and whole body workout), platform on which the app was available, developer's name, rank, number of ratings, cost, size, last update, and version.

\section{Application of Health Care Quality Indicators to Physical Activity Apps}

The methods of operationalizing the three quality indicators of safety, effectiveness, and provision of the most positive experience possible for the selected apps is described below.

\section{Safety of Physical Activity Apps}

For the safety indicator of health apps, privacy and security of users' data were considered. The privacy and security assessment was based on the recommendations of the Information Commissioners Office [33] and Online Trust Alliance [34]. It comprises of 8 questions evaluating the availability, accessibility of privacy policy, data gathering and sharing practices, and data security as is discussed in the privacy statement (see Multimedia Appendix 1 for data privacy and security assessment).

\section{Likelihood of Effectiveness of Physical Activity Apps}

As research on PA app efficacy is lacking, the likelihood of effectiveness was assessed by quantifying the presence of BCTs. Furthermore, many quality assessment procedures include an evaluation of the intervention development processes $[35,36]$. For example, involving key stakeholders in the development process is important to produce an intervention that meets user needs and increases the likelihood of intervention implementation [37]. Hence, data on the organizational affiliation of the developer, as well as expert and user involvement in the development process was collected. In addition, any evidence of scientific evaluation was also extracted.

\section{Behavior Change Techniques}

The BCT taxonomy v1 [38] was used to assess the number of BCTs in each app and the frequency of each BCT in the app sample overall. The coding manual provides guidelines to investigate the presence of 93 BCTs in behavior change interventions and has been used in previous studies that aimed to characterize BCTs in health apps [16,28,39-41]. In line with the instructions, we coded each BCT as Absent, Present + (BCT present in all probability but evidence unclear), and Present ++ (BCT present beyond all reasonably doubt). 
Table 1. The application of the health care quality indicators to physical activity apps.

\begin{tabular}{ll}
\hline Quality indicator of health care & Applying the indicator to health apps \\
\hline Safety & Privacy and security of data \\
Effectiveness & Behavior change techniques (Michie et al [38]) \\
& Development and evaluation process: Organizational affiliation; Expert involvement; User involvement; and \\
& Evidence of scientific evaluation \\
Positive experience & User ratings \\
& Usability \\
\hline
\end{tabular}

\section{Quality of Development Process and Evidence for Evaluation}

The evaluation of the quality of development process was based on the information provided in the app stores, the app website (if existent), and within the app itself. The following characteristics of the app content development were extracted: organizational affiliation (university, medical, government, or other nonprofit institutions); expert involvement (eg, fitness expert, behavior change specialist, and medical professional); and evidence for user involvement in the development of an app. The evidence for app evaluation was assessed by searching the name of the app in the following scientific databases: PubMed, ACM Digital Library, IEEE Xplore, and Google Scholar.

\section{Provision of the Most Positive Experience in Physical Activity Apps}

The provision of the most positive experience was operationalized using (1) the user ratings in app stores and (2) through formal usability assessment conducted by the two reviewers using the System Usability Scale (SUS) [42]. The average star rating (range: $1-5$ stars) was calculated by summing the number of stars and dividing them by the number of users who submitted ratings. SUS is a valid and reliable measure of overall usability (from 0-100) and consists of 10 items that are ranked on a 5-point Likert scale, from strongly disagree to strongly agree. The wording of the 8th statement was changed from cumbersome to awkward as recommended [43-45]. Second, the word system was replaced by app to make the scale applicable to the sample in this study. The interpretation of the SUS score used the thresholds proposed and validated by Bangor et al [43].

\section{Summary of Application of Quality Indicators}

The application of health care quality indicators to apps is summarized in Table 1.

\section{Interrater Reliability}

Interrater reliability for the presence or absence of the BCTs was ascertained by calculating Cohen kappa statistic [46] for each item. In addition, prevalence-adjusted bias-adjusted kappa (PABAK) [47] was assessed for the presence or absence of BCTs. The occurrence of high prevalence of negative agreement (when both rates agree that the BCT is absent) is very likely in the context of inclusion of BCTs in an app. When high prevalence of the identical response is seen, the kappa value results in low proportion of agreement, although the observed agreement is high [48]. The a priori strategy for assessing the sample was to complete the extraction of data for 10 apps to resolve any discrepancies in understanding of the measures before extracting the rest of data. Hence, the interrater reliability was assessed on 55 apps.

\section{Statistical Analysis}

The number of BCTs in the apps was summarized using the mean, standard deviation, median, $25^{\text {th }}$ and 75 th percentiles, and the maximum and minimum. Similar statistics were used to summarize user ratings, cost, size, and SUS score. Proportions were used to summarize the variables: data privacy and security, organization affiliation, expert and user involvement, and the evidence of evaluation in peer-reviewed journals.

The summary descriptive tables were presented for each store for free and paid apps separately and in total as app stores have separate rankings based on the cost. To assess if there was a difference in store characteristics between free and paid apps, $t$ tests were used to compare the average user ratings, size, and the number of BCTs; Wilcoxon test was used to compare the number of ratings; and Fisher exact was used for last update ( $<3$ months, 3-6 months, and >6 months), organizational affiliation, expert and user involvement, and presence of any peer-reviewed studies.

\section{Results}

\section{Sample Identification}

Out of 400 apps, 244 apps were excluded (209 apps did not target PA, 22 apps needed a peripheral device or paid membership to use the app, and 13 apps focused on multiple health behaviors), and 156 met the inclusion criteria (see Figure 1). A total of 31 duplicates were found. Subsequently, a sample of 125 unique apps was identified. A total of 65 apps, 32 free and 33 paid, were assessed.

\section{Sample Characteristics}

Descriptive data for the app sample are presented in Tables 2 and 3, whereas the data for each app separately is presented in Multimedia Appendix 2. There were no statistically significant differences in the number of ratings, cost, size, and last update between the free and paid apps in either iTunes or Google Play store. 
Figure 1. Flowchart of the apps included in the analysis. PA: physical activity.

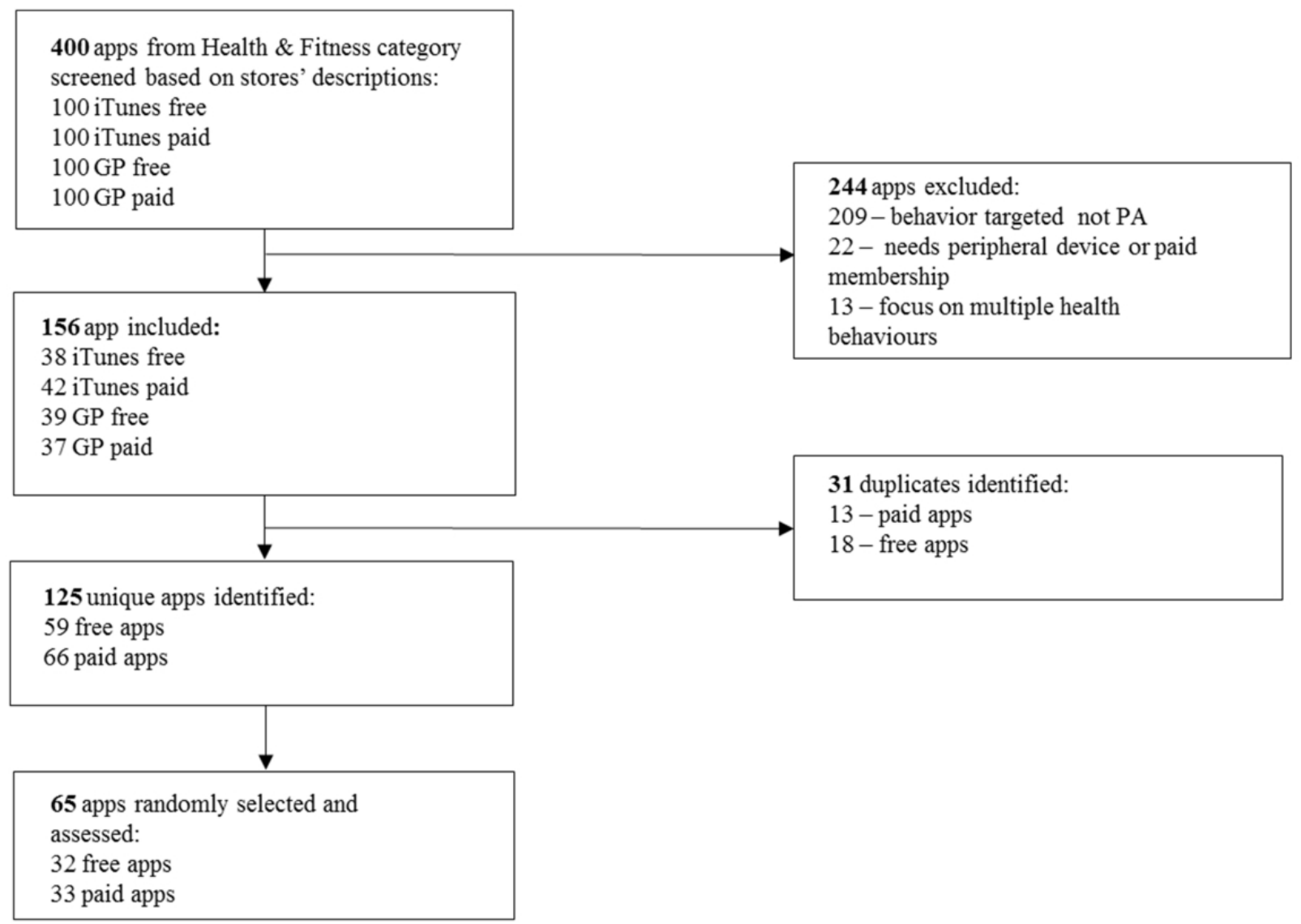


Table 2. Descriptive data for iTunes store.

\begin{tabular}{|c|c|c|c|c|}
\hline Descriptive data for iTunes & Free-iTunes $(\mathrm{N}=21)$ & Paid—iTunes $(\mathrm{N}=24)$ & Total—iTunes $(\mathrm{N}=45)$ & $P$ value \\
\hline \multicolumn{5}{|l|}{ Number of ratings } \\
\hline Mean (SD) & $3408.4(5848.4)$ & $773.7(1187.0)$ & $2031.2(4289.7)$ & .49 \\
\hline Median & 758 & 127 & 550 & \\
\hline 25-75 percentile & $438.0-3698.0$ & $47.0-1247.0$ & $85.5-1719.0$ & \\
\hline Min-max & $14-24530$ & $11-3845$ & $11-24530$ & \\
\hline \multicolumn{5}{|l|}{ Cost-iTunes $\left(G^{\prime} P^{a}\right)$} \\
\hline Mean (SD) & $\mathrm{N} / \mathrm{A}^{\mathrm{b}}$ & $2.5(1.5)$ & N/A & \\
\hline Median & N/A & 2.3 & N/A & \\
\hline 25-75 percentile & N/A & $1.5-3.0$ & N/A & \\
\hline Min-max & N/A & $1-8$ & N/A & \\
\hline \multicolumn{5}{|l|}{ Size of app (megabyte) } \\
\hline Mean (SD) & $88.4(49.8)$ & $94.9(75.4)$ & $91.8(64.1)$ & .74 \\
\hline Median & 74.3 & 83.3 & 82.2 & \\
\hline 25-75 percentile & $52.0-131.0$ & $61.7-102.0$ & $58.1-104.0$ & \\
\hline Min-max & $11-164$ & $9-376$ & $9-376$ & \\
\hline \multicolumn{5}{|l|}{ Last update } \\
\hline$<3$ months, $\mathrm{n}(\%)$ & $13(61.9)$ & $7(29.2)$ & $20(44.4)$ & .09 \\
\hline 3-6 months, n (\%) & $3(14.3)$ & $7(29.2)$ & $10(22.2)$ & \\
\hline
\end{tabular}

${ }^{\mathrm{a}} \mathrm{GBP}$ : British pound.

${ }^{\mathrm{b}} \mathrm{N} / \mathrm{A}$ : not applicable. 
Table 3. Descriptive data for Google Play store.

\begin{tabular}{|c|c|c|c|c|}
\hline Descriptive data for Google Play & Free-Google Play $(\mathrm{N}=21)$ & Paid-Google Play $(\mathrm{N}=16)$ & Total—Google Play $(\mathrm{N}=37)$ & $P$ value \\
\hline \multicolumn{5}{|l|}{ Number of ratings } \\
\hline Mean (SD) & $119000.7(165085.0)$ & $14457.9(43700.8)$ & $73793.0(136723.2)$ & $>.99$ \\
\hline Median & 44923 & 1720.5 & 5856 & \\
\hline 25-75 percentile & $5827.0-199596.0$ & $384.5-6452.0$ & $1475.0-78204.0$ & \\
\hline Min-max & $206-625077$ & $7-177277$ & $7-625077$ & \\
\hline \multicolumn{5}{|l|}{ Cost-Google Play $\left(G P^{a}\right)$} \\
\hline Mean (SD) & $\mathrm{N} / \mathrm{A}^{\mathrm{b}}$ & $3.6(2.3)$ & N/A & \\
\hline Median & N/A & 2.7 & N/A & \\
\hline 25-75 percentile & N/A & $2.3-5.0$ & N/A & \\
\hline Min-max & N/A & $1-9$ & N/A & \\
\hline \multicolumn{5}{|l|}{ Size of app (megabyte) } \\
\hline Mean (SD) & $28.4(21.2)$ & $43.4(34.2)$ & $34.9(28.2)$ & .11 \\
\hline Median & 26.8 & 31.5 & 29.6 & \\
\hline 25-75 percentile & $12.2-38.5$ & $27.7-54.0$ & $15.4-43.9$ & \\
\hline Min-max & $2-73$ & $1-145$ & $1-145$ & \\
\hline \multicolumn{5}{|l|}{ Last update } \\
\hline$<3$ months, $\mathrm{n}(\%)$ & $16(76)$ & $7(44)$ & $23(62)$ & .12 \\
\hline 3-6 months, $\mathrm{n}(\%)$ & $1(5)$ & $3(19)$ & $4(11)$ & \\
\hline$>6$ months, $\mathrm{n}(\%)$ & $4(19)$ & $6(38)$ & $10(27)$ & \\
\hline
\end{tabular}

${ }^{\mathrm{a}} \mathrm{GBP}$ : British pound.

${ }^{\mathrm{b}} \mathrm{N} / \mathrm{A}$ : not applicable.

The apps were categorized into five groups according to their primary focus. These were as follows: workout apps that demonstrate various exercises $(31 / 65,47 \%)$, tracking of movement apps that provide mapping of the running or walking or cycling routes $(13 / 65,20 \%)$, running programs that have prespecified goals reached by incremental increase in run-to-walk ratio $(12 / 65,18 \%)$, pedometers-based apps that count steps $(6 / 65,9 \%)$, and interval timers that enable the user to time their work or rest period $(3 / 65,4 \%)$.

\section{Data Privacy and Security}

\section{Availability and Accessibility of Privacy Policy}

The privacy policy was available for $46(70 \%, 46 / 65)$ apps overall. In one case, the link to the privacy policy was provided but did not work, and the app was indicated as not having a privacy policy. Of those that had privacy policy, only 4 (8\%, 4/46) apps had a short form privacy and security notice that highlighted key data practices that were disclosed in detail in the full privacy policy (see Table 4). There were nine instances where the short form notice was not applicable because of the policy already being concise. Multilingual policies were rare, with only 5 apps having a policy in another language. Apps that were developed outside the United Kingdom were more likely to provide multilingual policies.

\section{Data Gathering and Sharing}

Most of the apps (80\%) reported collecting personally identifiable information. In one instance, the developer did not discuss the data gathering practices. In 34 instances $(80 \%$, 34/46), the developers stated that they share the data they gather with 3 rd parties. There were two instances where the developer did not discuss data sharing practices. In many cases, the policies stated that "data shall not be shared, except for" followed by a list of exceptions that were vague and general. In these instances, the reviewers considered that the data were shared by the $3 \mathrm{rd}$ party.

\section{Data Security}

Only 41\% (19/46) of the apps described how the users' data were protected. The privacy policies stated that data safety is important to their practices but did not provide information on how data security was ensured.

\section{The Presence of Behavior Change Techniques}

There was "almost perfect" agreement between the reviewers for the coding of BCT presence or absence: $\mathrm{PABAK}=0.94,95 \%$ CI 0.93-0.95, kappa=.78 ("substantial"), 95\% CI 0.75-0.81. 
Table 4. Data gathering, sharing and security as described in the privacy policy (within those that had the policy, N=46). Note: $29 \%$ (19/65) did not have a privacy policy available.

\begin{tabular}{|c|c|c|c|}
\hline Data gathering, sharing, and security as described in the privacy policy & Free $(\mathrm{N}=24), \mathrm{n}(\%)$ & Paid $(\mathrm{N}=22), \mathrm{n}(\%)$ & Total $(\mathrm{N}=46), \mathrm{n}(\%)$ \\
\hline \multicolumn{4}{|l|}{ Is the privacy policy available without the need to download the app? } \\
\hline Yes & $24(100)$ & $22(100)$ & $46(100)$ \\
\hline \multicolumn{4}{|l|}{ Is the privacy policy available within the app? } \\
\hline No & $13(44)$ & $16(55)$ & $29(63)$ \\
\hline Yes & $11(64)$ & $6(35)$ & $17(36)$ \\
\hline \multicolumn{4}{|l|}{$\begin{array}{l}\text { Is there a short form notice (in plain English) highlighting key data } \\
\text { practices? }\end{array}$} \\
\hline No & $17(70)$ & $16(72)$ & $33(71)$ \\
\hline Yes & $4(16)$ & $0(0)$ & $4(8)$ \\
\hline Not applicable & $3(12)$ & $6(27)$ & $9(19)$ \\
\hline \multicolumn{4}{|l|}{ Is the privacy policy available in any other languages? } \\
\hline No & $20(83)$ & $21(95)$ & $41(89)$ \\
\hline Yes & $4(16)$ & $1(4)$ & $5(10)$ \\
\hline \multicolumn{4}{|l|}{ Does the app collect personally identifiable information? } \\
\hline No & $2(8)$ & $6(27)$ & $8(17)$ \\
\hline Yes & $21(87)$ & $16(72)$ & $37(80)$ \\
\hline Not specified & $1(4)$ & $0(0)$ & $1(2)$ \\
\hline \multicolumn{4}{|l|}{ Does the app share users' data with a 3rd party? } \\
\hline No & $2(8)$ & $8(36)$ & $10(22)$ \\
\hline Yes & $21(87)$ & $13(59)$ & $34(74)$ \\
\hline Not specified & $1(4)$ & $1(4)$ & $2(4)$ \\
\hline \multicolumn{4}{|l|}{$\begin{array}{l}\text { Does the app say how the users' data security is ensured? For example, } \\
\text { encryption, authentication, and firewall }\end{array}$} \\
\hline No & $13(54)$ & $14(63)$ & $27(58)$ \\
\hline Yes & $11(45)$ & $8(36)$ & $19(41)$ \\
\hline
\end{tabular}

Table 5. Descriptive statistics for the inclusion of the behavior change techniques (BCTs).

\begin{tabular}{lllll}
\hline Inclusion of the BCTs & Free $(\mathrm{N}=32)$ & Paid (N=33) & Total (N=65) & $P$ value \\
\hline Total BCTs & & & & $7.0(2.9)$ \\
Mean (SD) & $6.6(3.0)$ & $7.5(2.9)$ & 8 & .21 \\
Median & 7 & 8 & $5.0-9.0$ \\
25-75 percentile & $5.0-8.0$ & $6.0-10.0$ & $1-13$ \\
Min-max & $1-12$ & $1-13$ & \\
\hline
\end{tabular}

The total number of BCTs for free and paid apps sample was similar (see Table 5). Every app contained at least one BCT, and the maximum number of BCTs was 12 for free and 13 for paid apps. The median number of BCTs was 7 for free and 8 for paid apps (see Multimedia Appendix 3 for the graph of the distribution of the BCTs in apps).

Figure 2 shows the frequency of the common BCT groups. The "Feedback and monitoring" group was the most common, with $92.3 \%$ of apps containing at least one BCT of this group, most commonly "Feedback on behavior" and "Feedback on outcome(s) of behavior" BTCs. "Goals and planning" ("Goal setting" and "Action planning" BCTs) were also well represented at $84.6 \%$. More than half of the apps included BCTs from the "Comparison of behavior" group (66.2\%), which most likely was "Demonstration on the behavior" (see Figure 3 for the examples of the app features that included BCTs from the most common BCT groups). "Social support" (64.6\%), "Shaping knowledge" groups (60\%), and "Associations" (46.2\%) were common, but only one BCT from each of these groups were present. "Reward and threat" group (53.8\%) was common with two BCTs only ("Social reward" and "Nonspecific incentive"). Other BCT groups were rare: less than $15 \%$ of apps contained BCTs from the "Comparison of outcomes" group; "Natural 
consequences" and "Antecedents" represented 10.8\% and 6.2\% of the total BCTs, respectively. The remaining BCT groups were nonexistent in the PA apps. Multimedia Appendix 4 presents the frequency of individual BCTs within the groups' BCTs (BCTs that occurred in at least five apps are shown).

\section{Quality of App Development and Evaluation Process}

Only 1 app had a noncommercial affiliation, One You Couch to $5 K$, which was developed by Public Health England (see Table 6). None of the apps reported user involvement during development. Twelve out of 65 apps (4 free and 8 paid) consulted with experts to design the content of the app. Nine out of 23 free apps (28.1\%) had a study associated with the apps published in a peer-reviewed journal. In comparison, for only 3 paid apps (9.1\%), there was a peer-reviewed study found.

\section{Positive Experience}

\section{User Ratings}

The median user rating in iTunes was 4.4 and 4.5 in Google Play and did not differ between free and paid apps in either stores (see Table 7).
In both stores, the 25th percentile was around 4 stars (4.0 in iTunes and 4.4 in Google Play), suggesting that the user ratings tended to be high, and only $25 \%$ of ratings were below 4 stars. The histograms of star ratings in both stores (Figure 4) showed the skewness of the star average distribution.

\section{Usability}

The average SUS score for the apps was similar for both free and paid apps, with median of 86.3 (see Table 8). Using the descriptors suggested by Bangor et al [43], the score can be described as "excellent." Fifty percent of the total average SUS score fell between 75.0 and 92.5 , and $25 \%$ had a score higher than 92.5 , suggesting that more than $75 \%$ of the app sample assessed could be described as having "good" to "excellent" usability. See Multimedia Appendix 5 for the graph of the distribution of the SUS score averaged between the two reviewers.

Figure 2. Frequency of behavior change techniques (BCTs) incorporated by physical activity (PA) apps, presented by BCT groups.

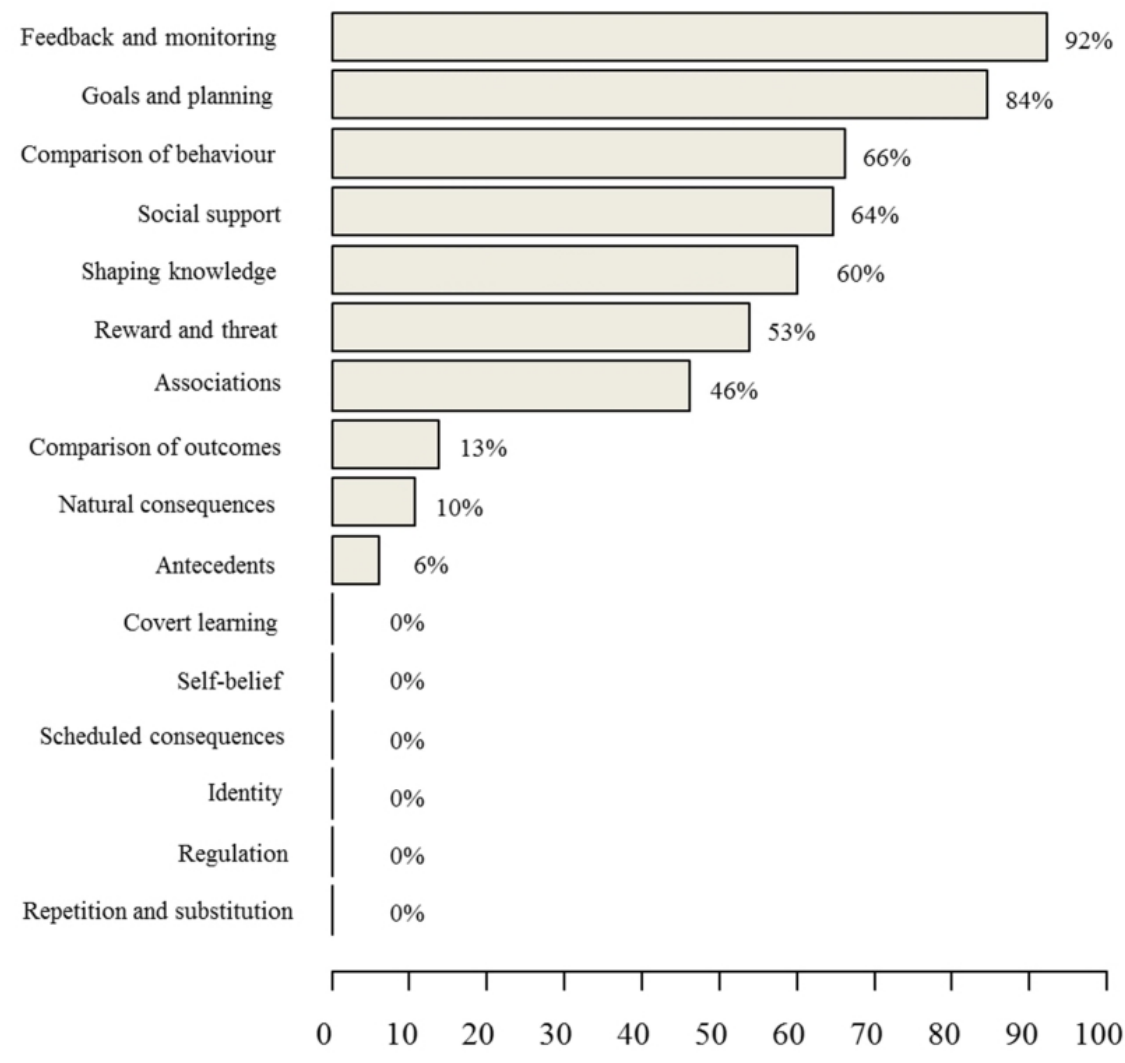


Figure 3. Examples of the most common behavior change techniques (BCTs) from the most frequent BCT groups: (1) goals and planning: 1.1 Goal setting (behavior), (2) feedback and monitoring: 2.2 Feedback on behavior, and (3) comparison of behavior: 6.1 Demonstration of the behavior.

\subsection{Goal-setting (behavior)}

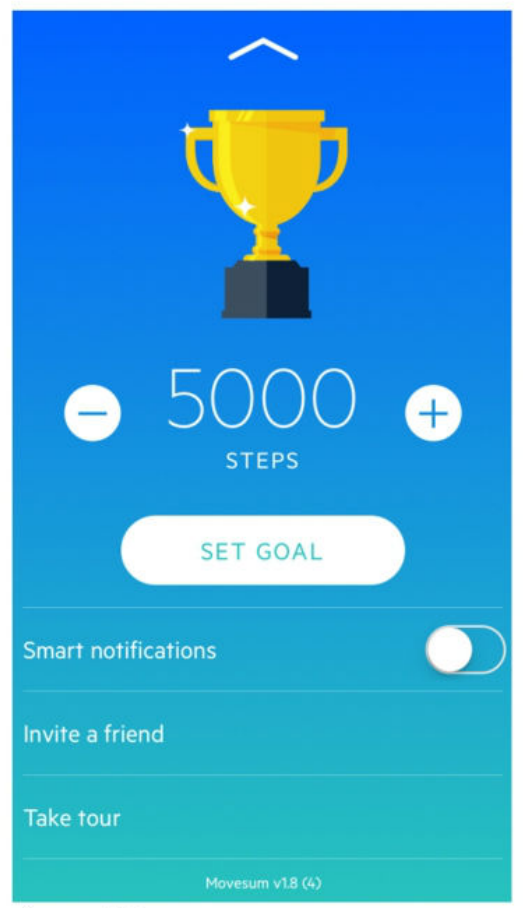

App: Movesum

\subsection{Feedback on behavior}

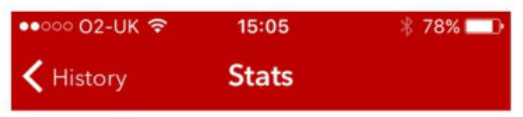

\begin{tabular}{l|l|l|l|} 
Days & Weeks & Months & Years \\
\hline
\end{tabular}

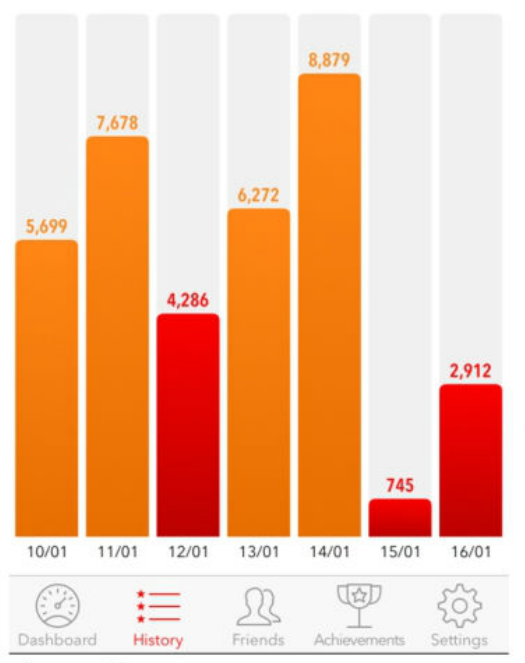

App: Stepz

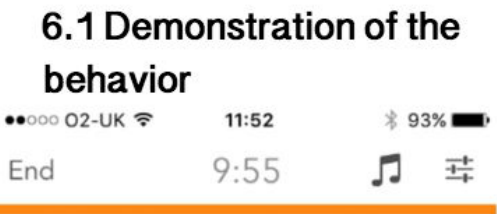

Front Kicks

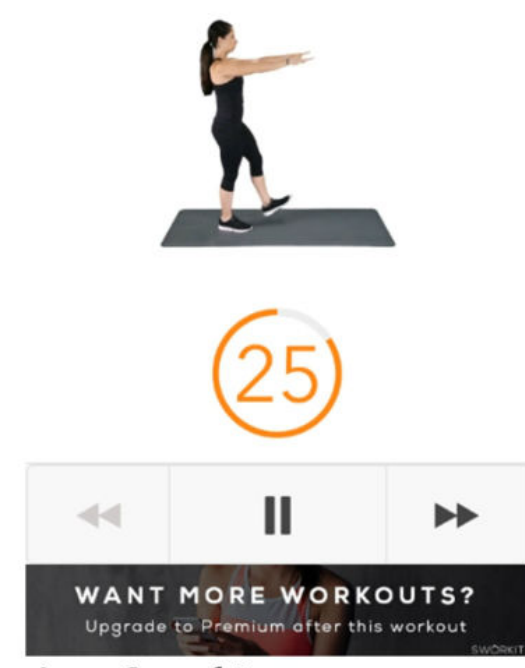

App: Sworkit

Table 6. Descriptive data for the quality of app development and evaluation process: organizational affiliation, expert and user involvement, and evidence of evaluation in peer-reviewed journals.

\begin{tabular}{|c|c|c|c|c|}
\hline The quality of app development and evaluation process & Free $(\mathrm{N}=32), \mathrm{n}(\%)$ & Paid $(\mathrm{N}=33), \mathrm{n}(\%)$ & Total $(\mathrm{N}=65), \mathrm{n}(\%)$ & $P$ value \\
\hline \multicolumn{5}{|l|}{ Any affiliation } \\
\hline Commercial & $31(96)$ & $33(100)$ & $64(98)$ & .49 \\
\hline Government institution & $1(3)$ & $0(0)$ & $1(1)$ & \\
\hline \multicolumn{5}{|l|}{ Any expert } \\
\hline No & $28(87)$ & $25(75)$ & $53(81)$ & .34 \\
\hline Yes & $4(12)$ & $8(24)$ & $12(18)$ & \\
\hline \multicolumn{5}{|l|}{ Any user involvement } \\
\hline No & $32(100)$ & $33(100)$ & $65(100)$ & \\
\hline \multicolumn{5}{|l|}{ Any peer journal } \\
\hline No & $23(71)$ & $30(90)$ & $53(81)$ & .06 \\
\hline Yes & $9(28)$ & $3(9)$ & $12(18)$ & \\
\hline
\end{tabular}


Table 7. Descriptive statistics for user ratings (1-5 stars) in iTunes and Google Play.

\begin{tabular}{llll}
\hline User ratings & Free & Paid & Total \\
\hline iTunes & $(\mathrm{N}=21)$ & $(\mathrm{N}=24)$ & $(\mathrm{N}=45)$ \\
Mean (SD) & $4.1(0.8)$ & $4.3(0.6)$ & $4.2(0.7)$ \\
Median & 4.4 & 4.6 & 4.4 \\
25-75 percentile & $4.0-4.6$ & $4.0-4.8$ & $4.0-4.6$ \\
Min-max & $2-5$ & $3-5$ & $2-5$ \\
Google Play & $(\mathrm{N}=21)$ & $(\mathrm{N}=16)$ & $(\mathrm{N}=37)$ \\
Mean (SD) & $4.4(0.5)$ & $4.4(0.3)$ & $4.4(0.4)$ \\
Median & 4.5 & 4.5 & 4.5 \\
25-75 percentile & $4.4-4.6$ & $4.4-4.6$ & $4.4-4.6$ \\
Min-max & $2-5$ & $4-5$ & $2-5$ \\
\hline
\end{tabular}

Figure 4. Distribution of user ratings in iTunes and Google Play.

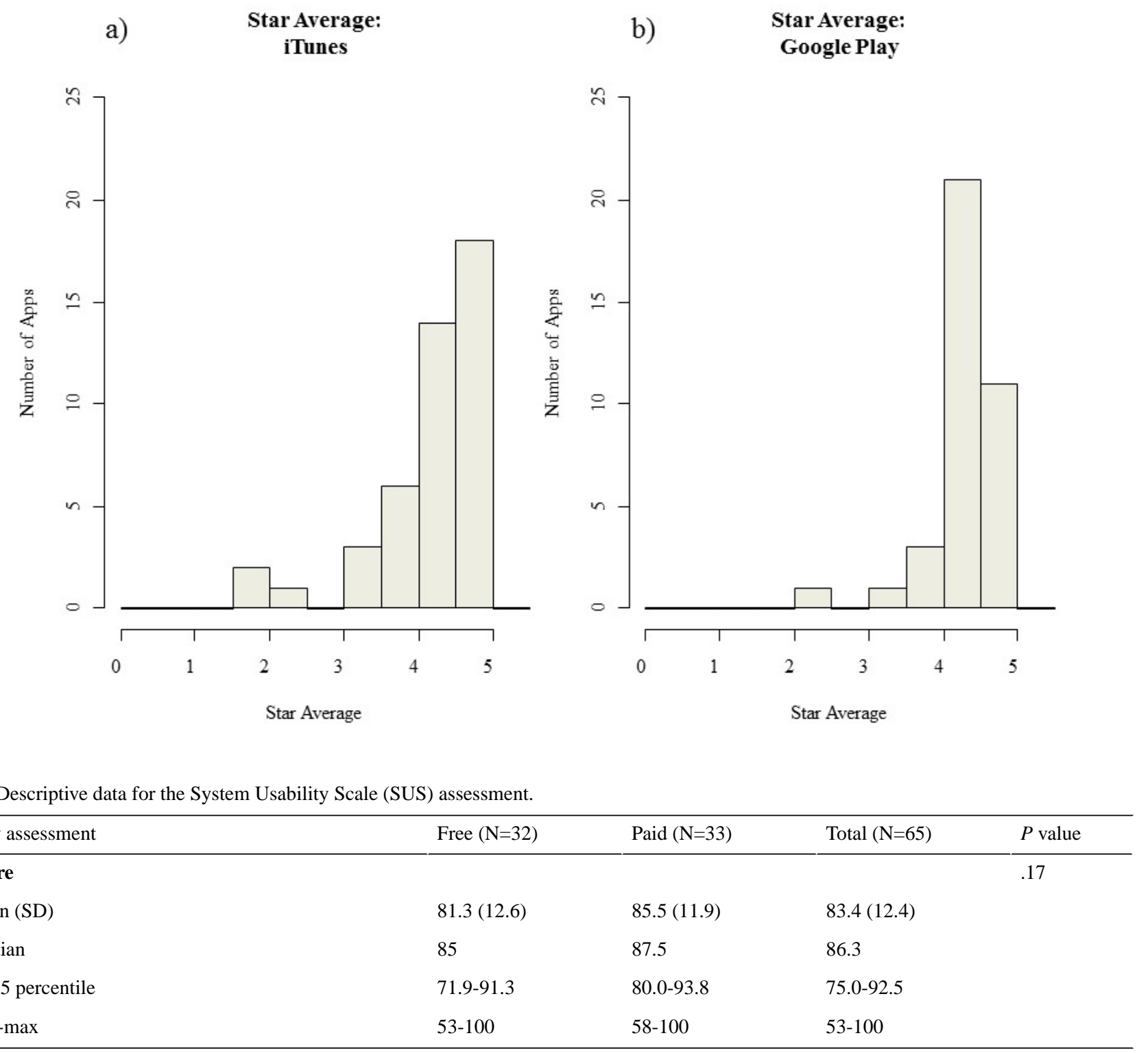




\section{Discussion}

\section{Principal Findings}

This study described the most popular PA apps on the market, focusing on the quality determinants of safety (data privacy and security), effectiveness (BCTs and development and evaluation quality), and provision of the most positive experience possible (user ratings and usability). Overall, our findings suggest that most of the apps in this sample were of reasonable quality in terms of the user experience, but there were substantial shortcomings in the areas of safety and effectiveness. The assessment of data privacy and security showed that the privacy policy was not available for $29.2 \%$ of the apps. Most apps collected personally identifiable information, shared users' data with a third party, and more than half of the apps did not specify how they ensure data security. Every app contained at least one BCT, with an average of 7 . The maximum number of BCTs was 13 , and the most common BCTs related to provision of feedback on behavior. All but one app had commercial affiliation, 12 consulted an expert, and none reported involving users in the app development. Only 12 of 65 apps had a peer-reviewed study connected to the app but only one app was assessed for efficacy in a trial [49]. User ratings were high, with only a quarter of the ratings falling below 4 stars. Similarly, the usability scores were "good" to "excellent." There was no statistically significant difference between free and paid apps on the characteristics or quality indicators.

\section{Safety of Apps}

The assessment of privacy policy showed that privacy and security of users' data could be substantially improved. Our results are consistent with previous studies assessing data safety. Huckvale et al [8], who assessed the apps from the NHS Apps Library, found that $20 \%$ of apps did not have privacy policy, and most of the apps breached users' data privacy and security. Collecting and analyzing consumer data by app developers can have advantages for the users, such as personalization and improvement of the products [35]. However, the information about these practices ought to be transparent and understandable [36] to enable the potential user to make an informed decision to download the app. Regulatory oversight concerning data protection is challenging because of the large scale of the app market. In consequence, ensuring the privacy and security of data is left in the hands of app developers [50].

\section{Likelihood of Effectiveness}

The apps in the review contained, on average, 7 BCTs. The results of this study are similar to those found in previous reviews of PA apps: Middelweerd et al [17] found that, on average, 5 BCTs were used in each app; Conroy et al [16] reported between 1 and 13 BCTs with a mean of 4.2; and a study using the same BCT taxonomy as the one in this study found, on average, 6.6 BCTs [18].

The most common BCTs were feedback and monitoring, goal setting, and action planning. These self-regulation strategies have been shown to be effective in increasing PA behavior $[51,52]$. However, the BCTs from 9 out of 16 BCT groups were present constituted $14 \%$ of the current BCT taxonomy.

The effect of the number of BCTs on efficacy of the interventions remains inconclusive. Although there is some evidence that higher number of BCTs produces larger effect sizes in Web-based interventions [53], others show no effect [51]. The evidence of what BCTs are most likely to increase the likelihood of behavior change is unknown. It is possible that certain BCTs are more efficacious when present together producing a synergistic effect [54]. The use of variety of BCTs groups, as well as the techniques within the BCT group, would theoretically increase effectiveness by addressing various barriers to PA. For example, within the "Goals and planning" BCT group, only 3 out of 9 BCTs were utilized. Implementing features that utilize other BCTs that enable goal setting and planning (eg, problem-solving technique, asking the user to commit to their goal, and providing an opportunity for the user to review their goal) might increase the likelihood of effectiveness of the app.

The use of evidence and theoretical frameworks is vital in developing behavior change interventions [55]. The COM-B (capability, opportunity, motivation, and behavior) model of behavior change [56] enables developers to systematically identify the barriers and facilitators of the behavior targeted and to select intervention components that will address these barriers to increase the likelihood of behavior change.

The results suggest that the quality of the app development and evaluation process could be improved. We did not find any evidence of user involvement, and most apps were commercially developed with the rare involvement of experts. Similar results were found in previous reviews [28,57], and there is evidence to suggest that expert involvement predict the number of app download [58]. Indeed, the user-centered design framework stresses the importance of understanding the contextual experiences of potential users, as well as inclusion of multidisciplinary skills and perspectives when developing products and services. Our results also support previous research showing the lack of evidence for scientific evaluation of the apps on the market [59,60]. We found only 12 studies in peer-reviewed journals that were associated with the apps. However, only one app was used in a pragmatic RCT [49], and the study was not conducted by the app developer.

\section{Positive Experience}

The usability of the apps reviewed was high. Likewise, user ratings of the PA apps were high, with only a quarter of the ratings receiving less than 4 stars. Similarly, Mendiola et al [61] found that usability was related to user ratings in a general sample of health apps. The competition for customer in the app stores is high, with $90 \%$ of apps in the app stores not attracting enough attention to feature in the ranking of the app stores and consequently not visible for the user, called "App Zombies" [62]. High-quality graphic design, visual appeal, and ease of use are more likely to attract potential customers to download and engage with the app. However, it is unknown whether these variables relate to effectiveness of the apps. There is evidence to suggest that Web-based interventions with higher usability tend to be more effective [54]. However, continued engagement 
with an app may suggest engagement with the intervention or unhealthy dependence [63].

\section{Strengths}

The strengths of this study include a systematic approach to sample identification and assessment. First, the sample of apps was identified by screening 400 apps in two major app distribution platforms, including both free and paid apps. Second, the sample was identified and assessed by 2 independent reviewers. Third, the assessment tools covered various aspects of quality, both inclusion of theory as well as user experience using subjective (user ratings) and objective (usability) measures.

\section{Limitations}

First, it is unknown what variables are included in the ranking algorithm of the top apps from which the sample was selected. It is likely that usage data and user ratings comprise the ranking [26], but other unknown variables may also be included. Second, the possibility that user ratings were influenced by fake reviews cannot be excluded. [64,65]. However, there is a reliance on genuine users of the app to mark it down if the app does not live to their expectations, and this review included popular apps with high number of ratings (2.8 million). Third, data privacy and security assessment was limited to the analysis of the policy. There is evidence of inconsistency between the policy statement and the actual practices of app developers [8]. Fourth, the quality of app development process was based on the information provided in the app stores, the app website, and within the app itself; hence, it is possible that some data were missed if they were not available on the Web. Finally, the evidence for app evaluation was assessed by searching the name of the app in the popular scientific databases. If the name of the app was absent in the title or abstract, then the relevant paper would not have been found.

\section{Implications}

More studies are needed to assess what predicts higher user rating. It is unknown what features or characteristics of apps users like and perceive to be effective in increasing their PA. It is possible that there is a discrepancy between what is liked and what is more likely to be effective. Second, research is needed to understand the use of PA apps to design effective digital tools. There is little knowledge concerning how users adopt these apps into their routines and what are the facilitators and barriers to increasing PA using apps. Third, the optimal number of BCTs in PA app remains unknown. It is likely that different BCTs may be more suitable for different modes of delivery (face-to-face, Web-based, and app), For example, social support might produce better results when delivered face-to-face rather than via an app. Alternatively, automatic monitoring and feedback on PA in apps can facilitate self-regulation and may be considered as a more efficient method than self-monitoring using diaries.

Although popularity of the apps is high, health care professionals and potential users need to be aware of the limitation in the safety of personal data, as well as the limitation in the quality of the apps to change behavior. Currently, it is not possible to recommend apps that are most effective, but attempts to create a database of high-quality apps are in progress. For example, the National Information Board is developing an app accreditation model that consists of a 4-stage assessment framework that aims to establish a database of high-quality health apps [66].

\section{Conclusions}

This study examined the quality of the most popular PA apps currently available on the market. Although usability and user ratings of app were high, there was a concerning lack of safety controls for users' personal data for the majority of the apps, the apps included limited number of BCTs that mostly related to feedback on behavior, and the quality of the content and development processes were suboptimal. The technological development and the potential for profit far outpaced the research on the ability of these apps to support PA behavior change. With 165,000 apps on the market, this represents a loss of opportunity for health promotion on a large scale.

\section{Acknowledgments}

The authors would like to thank Lou Atkins, Senior Teaching Fellow, Department of Clinical, Educational and Health Psychology, University College London, London, UK, who was consulted on the BCT coding. PK is a PhD student at University College London, funded by the Medical Research Council.

\section{Conflicts of Interest}

None declared.

\section{Multimedia Appendix 1}

Data privacy and security assessment based in the content of privacy policy.

[PDF File (Adobe PDF File), 99KB-Multimedia Appendix 1]

\section{Multimedia Appendix 2}

Individual-level data for the sample of apps assessed.

[PDF File (Adobe PDF File), 649KB-Multimedia Appendix 2] 


\section{Multimedia Appendix 3}

Graph of the distribution of the BCTs in PA apps.

[JPG File, 52KB-Multimedia Appendix 3]

\section{Multimedia Appendix 4}

Frequency of individual BCTs within the groups BCTs (BCTs that occurred in at least five apps are shown).

[JPG File, 217KB-Multimedia Appendix 4]

\section{Multimedia Appendix 5}

Graph of the distribution of the SUS score averaged between the two reviewers.

[PDF File (Adobe PDF File), 101KB-Multimedia Appendix 5]

\section{References}

1. Pedersen BK, Saltin B. Exercise as medicine - evidence for prescribing exercise as therapy in 26 different chronic diseases. Scand J Med Sci Sports 2015 Dec;25(Suppl 3):1-72. [doi: 10.1111/sms.12581] [Medline: 26606383]

2. Knols R, Aaronson NK, Uebelhart D, Fransen J, Aufdemkampe G. Physical exercise in cancer patients during and after medical treatment: a systematic review of randomized and controlled clinical trials. J Clin Oncol 2005 Jun 01;23(16):3830-3842. [doi: 10.1200/JCO.2005.02.148] [Medline: 15923576]

3. Booth FW, Roberts CK, Laye MJ. Lack of exercise is a major cause of chronic diseases. Compr Physiol 2012 Apr;2(2):1143-1211 [FREE Full text] [doi: 10.1002/cphy.c110025] [Medline: 23798298]

4. Chen JJ, Lee Y. Physical activity for health: evidence, theory, and practice. J Prev Med Public Health 2013 Jan;46(Suppl 1):S1-S2 [FREE Full text] [doi: 10.3961/jpmph.2013.46.S.S1] [Medline: 23413397]

5. Zschucke E, Gaudlitz K, Ströhle A. Exercise and physical activity in mental disorders: clinical and experimental evidence. J Prev Med Public Health 2013 Jan;46(Suppl 1):S12-S21 [FREE Full text] [doi: 10.3961/jpmph.2013.46.S.S12] [Medline: 23412549]

6. Hallal PC, Andersen LB, Bull FC, Guthold R, Haskell W, Ekelund U, Lancet Physical Activity Series Working Group. Global physical activity levels: surveillance progress, pitfalls, and prospects. Lancet 2012 Jul 21;380(9838):247-257. [doi: 10.1016/S0140-6736(12)60646-1] [Medline: 22818937]

7. Dzewaltowski DA, Estabrooks PA, Glasgow RE. The future of physical activity behavior change research: what is needed to improve translation of research into health promotion practice? Exerc Sport Sci Rev 2004 Apr;32(2):57-63. [Medline: 15064649]

8. Huckvale K, Prieto JT, Tilney M, Benghozi P, Car J. Unaddressed privacy risks in accredited health and wellness apps: a cross-sectional systematic assessment. BMC Med 2015;13:214 [FREE Full text] [doi: 10.1186/s 12916-015-0444-y] [Medline: 26404673]

9. Price M, Yuen EK, Goetter EM, Herbert JD, Forman EM, Acierno R, et al. mHealth: a mechanism to deliver more accessible, more effective mental health care. Clin Psychol Psychother 2014;21(5):427-436 [FREE Full text] [doi: 10.1002/cpp.1855] [Medline: 23918764]

10. Pew Internet. African Americans and technology use URL: http://www.pewinternet.org/files/2014/01/ African-Americans-and-Technology-Use.pdf [accessed 2016-05-05] [WebCite Cache ID 6tk0yhui5]

11. Office for National Statistics. 2017. Internet access-households and individuals URL: https://www.ons.gov.uk/ peoplepopulationandcommunity/householdcharacteristics/homeinternetandsocialmediausage/bulletins/ internetaccesshouseholdsandindividuals/2017 [accessed 2017-10-01] [WebCite Cache ID 6ua1cz5xB]

12. Glasgow RE, Bull SS, Piette JD, Steiner JF. Interactive behavior change technology: a partial solution to the competing demands of primary care. Am J Prev Med 2004 Aug;27(2 Suppl):80-87. [doi: 10.1016/j.amepre.2004.04.026] [Medline: 15275676]

13. Research2Guidance. 2014. mHealth app developer economics 2014 URL: http://research2guidance.com/product/ mhealth-app-developer-economics-2014/ [accessed 2017-09-25] [WebCite Cache ID 6tk2FAJel]

14. BinDhim NF, Hawkey A, Trevena L. A systematic review of quality assessment methods for smartphone health apps. Telemed J E Health 2015 Feb;21(2):97-104. [doi: 10.1089/tmj.2014.0088] [Medline: 25469795]

15. Direito A, Carraça E, Rawstorn J, Whittaker R, Maddison R. mHealth Technologies to influence physical activity and sedentary behaviors: behavior change techniques, systematic review and meta-analysis of randomized controlled trials. Ann Behav Med 2017 Apr;51(2):226-239. [doi: 10.1007/s12160-016-9846-0] [Medline: 27757789]

16. Conroy DE, Yang CH, Maher JP. Behavior change techniques in top-ranked mobile apps for physical activity. Am J Prev Med 2014 Jun;46(6):649-652. [doi: 10.1016/j.amepre.2014.01.010] [Medline: 24842742] 
17. Middelweerd A, Mollee JS, van der Wal CN, Brug J, Te Velde SJ. Apps to promote physical activity among adults: a review and content analysis. Int J Behav Nutr Phys Act 2014;11:97 [FREE Full text] [doi: 10.1186/s12966-014-0097-9] [Medline: 25059981]

18. Yang C, Maher JP, Conroy DE. Implementation of behavior change techniques in mobile applications for physical activity. Am J Prev Med 2015 Apr;48(4):452-455. [doi: 10.1016/j.amepre.2014.10.010] [Medline: 25576494]

19. Knight E, Stuckey MI, Prapavessis H, Petrella RJ. Public health guidelines for physical activity: is there an app for that? A review of android and apple app stores. JMIR Mhealth Uhealth 2015;3(2):e43 [FREE Full text] [doi: 10.2196/mhealth.4003] [Medline: 25998158]

20. Bardus M, Smith JR, Samaha L, Abraham C. Mobile phone and web 2.0 technologies for weight management: a systematic scoping review. J Med Internet Res 2015;17(11):e259 [FREE Full text] [doi: 10.2196/jmir.5129] [Medline: 26573984]

21. Gravenhorst F, Muaremi A, Bardram J, Grünerbl A, Mayora O, Wurzer G, et al. Mobile phones as medical devices in mental disorder treatment: an overview. Pers Ubiquitous Comput 2014 Sep 21;19(2):335-353. [doi: 10.1007/s00779-014-0829-5]

22. Campbell SM, Roland MO, Buetow SA. Defining quality of care. Soc Sci Med 2000 Dec;51(11):1611-1625. [Medline: 11072882]

23. Maxwell RJ. Quality assessment in health. Br Med J (Clin Res Ed) 1984 May 12;288(6428):1470-1472 [FREE Full text] [Medline: $\underline{6426606]}$

24. Donabedian A. The quality of care. How can it be assessed? J Am Med Assoc 1988;260(12):1743-1748. [Medline: $\underline{3045356]}$

25. Department of Health. 2008. High quality care for all: NHS next stage review final report URL: https://www.gov.uk/ government/publications/high-quality-care-for-all-nhs-next-stage-review-final-report [accessed 2017-10-01] [WebCite Cache ID 6tk2SKca8]

26. Waltz A. Moz. 2015 May 27. Deconstructing the app store rankings formula with a little mad science URL: https://moz. com/blog/app-store-rankings-formula-deconstructed-in-5-mad-science-experiments [accessed 2018-02-15] [WebCite Cache ID 6xFD9TS31]

27. Infront. Value of organic first-page results 2015 URL: https://www.infront.com/blogs/the-infront-blog/2015/6/17/ value-of-first-page-google-results [accessed 2017-09-25] [WebCite Cache ID 6tk3VmF4t]

28. Chen J, Cade JE, Allman-Farinelli M. The most popular smartphone apps for weight loss: a quality assessment. JMIR Mhealth Uhealth 2015;3(4):e104 [FREE Full text] [doi: 10.2196/mhealth.4334] [Medline: 26678569]

29. Azar KM, Lesser LI, Laing BY, Stephens J, Aurora MS, Burke LE, et al. Mobile applications for weight management: theory-based content analysis. Am J Prev Med 2013 Nov;45(5):583-589. [doi: 10.1016/j.amepre.2013.07.005] [Medline: 24139771]

30. Breton ER, Fuemmeler BF, Abroms LC. Weight loss-there is an app for that! But does it adhere to evidence-informed practices? Transl Behav Med 2011 Dec;1(4):523-529 [FREE Full text] [doi: 10.1007/s13142-011-0076-5] [Medline: 24073074]

31. Cowan LT, Van Wagenen SA, Brown BA, Hedin RJ, Seino-Stephan Y, Hall PC, et al. Apps of steel: are exercise apps providing consumers with realistic expectations?: a content analysis of exercise apps for presence of behavior change theory. Health Educ Behav 2013 Apr;40(2):133-139. [doi: 10.1177/1090198112452126] [Medline: 22991048]

32. West JH, Hall PC, Hanson CL, Barnes MD, Giraud-Carrier C, Barrett J. There's an app for that: content analysis of paid health and fitness apps. J Med Internet Res 2012;14(3):e72 [FREE Full text] [doi: 10.2196/jmir.1977] [Medline: 22584372]

33. Information Commissioner's Office. 2013. Privacy in mobile apps URL: https://ico.org.uk/media/for-organisations/documents/ 1596/privacy-in-mobile-apps-dp-guidance.pdf [accessed 2017-09-25] [WebCite Cache ID 6tk3cjdfA]

34. Online Trust Alliance. 2014. Mobile App Privacy \& Security URL: https://otalliance.org/best-practices/ mobile-app-privacy-security [accessed 2018-02-14] [WebCite Cache ID 6xEYd7pet]

35. National Institute for HealthCare Excellence. NICE. 2014 Jan 02. Behavior change: individual approaches URL: https:/ /www.nice.org.uk/guidance/ph49/chapter/What-is-this-guidance-about [accessed 2017-10-01] [WebCite Cache ID 6tk3dtx4L]

36. Singh K, Drouin K, Newmark LP, Rozenblum R, Lee J, Landman A, et al. Developing a framework for evaluating the patient engagement, quality, and safety of mobile health applications. Issue Brief (Commonw Fund) 2016 Feb;5:1-11. [Medline: 26934758]

37. Craig P, Dieppe P, Macintyre S, Michie S, Nazareth I, Petticrew M, Medical Research Council Guidance. Developing and evaluating complex interventions: the new Medical Research Council guidance. Br Med J 2008;337:a1655 [FREE Full text] [Medline: $\underline{18824488}$ ]

38. Michie S, Richardson M, Johnston M, Abraham C, Francis J, Hardeman W, et al. The behavior change technique taxonomy (v1) of 93 hierarchically clustered techniques: building an international consensus for the reporting of behavior change interventions. Ann Behav Med 2013 Aug;46(1):81-95. [doi: 10.1007/s12160-013-9486-6] [Medline: 23512568]

39. Crane D, Garnett C, Brown J, West R, Michie S. Behavior change techniques in popular alcohol reduction apps: content analysis. J Med Internet Res 2015;17(5):e118 [FREE Full text] [doi: 10.2196/jmir.4060] [Medline: 25977135]

40. Bardus M, van Beurden SB, Smith JR, Abraham C. A review and content analysis of engagement, functionality, aesthetics, information quality, and change techniques in the most popular commercial apps for weight management. Int J Behav Nutr Phys Act 2016;13(1):35 [FREE Full text] [doi: 10.1186/s12966-016-0359-9] [Medline: 26964880] 
41. Direito A, Dale LP, Shields E, Dobson R, Whittaker R, Maddison R. Do physical activity and dietary smartphone applications incorporate evidence-based behaviour change techniques? BMC Public Health 2014;14:646 [FREE Full text] [doi: 10.1186/1471-2458-14-646] [Medline: 24965805]

42. Brooke J. Hell.meiert. Reading, UK: Digital Equipment Co Ltd; 1986. System usability scale (SUS): a quick-and-dirty method of system evaluation user information URL: https://hell.meiert.org/core/pdf/sus.pdf [accessed 2018-02-15] [WebCite Cache ID 6xFI7FGOo]

43. Bangor A, Kortum PT, Miller JT. An empirical evaluation of the system usability scale. Int J Hum Comput Interact 2008 Jul 30;24(6):574-594. [doi: 10.1080/10447310802205776]

44. Finstad K. The system usability scale and non-native english speakers. J Usability Stud 2006;1(4):185-188.

45. Lewis JR. Psychometric evaluation of the PSSUQ using data from five years of usability studies. Int J Hum Comput Interact 2011 Jun;14(3-4):463-488. [doi: 10.1080/10447318.2002.9669130]

46. McHugh ML. Interrater reliability: the kappa statistic. Biochemia Medica 2012;22(3):276-282. [doi: 10.11613/BM.2012.031]

47. Byrt T, Bishop J, Carlin JB. Bias, prevalence and kappa. J Clin Epidemiol 1993 May;46(5):423-429. [doi: 10.1016/0895-4356(93)90018-V]

48. Cunningham M. SAS. 2009. More than just the kappa coefficient: a program to fully characterize inter-rater reliability between two raters URL: http://support.sas.com/resources/papers/proceedings09/242-2009.pdf [accessed 2018-02-15] [WebCite Cache ID 6xFLjlmYO]

49. Direito A, Jiang Y, Whittaker R, Maddison R. Apps for improving FITness and increasing physical activity among young People: the AIMFIT pragmatic randomized controlled trial. J Med Internet Res 2015;17(8):e210 [FREE Full text] [doi: 10.2196/jmir.4568] [Medline: 26316499]

50. Wicks P, Chiauzzi E. 'Trust but verify'--five approaches to ensure safe medical apps. BMC Med 2015;13:205 [ㅌREE Full text] [doi: 10.1186/s12916-015-0451-z] [Medline: 26404791]

51. Michie S, Abraham C, Whittington C, McAteer J, Gupta S. Effective techniques in healthy eating and physical activity interventions: a meta-regression. Health Psychol 2009 Nov;28(6):690-701. [doi: 10.1037/a0016136] [Medline: 19916637]

52. Pearson ES. Goal setting as a health behavior change strategy in overweight and obese adults: a systematic literature review examining intervention components. Patient Educ Couns 2012 Apr;87(1):32-42. [doi: 10.1016/j.pec.2011.07.018] [Medline: $\underline{21852063}$

53. Webb TL, Joseph J, Yardley L, Michie S. Using the internet to promote health behavior change: a systematic review and meta-analysis of the impact of theoretical basis, use of behavior change techniques, and mode of delivery on efficacy. $\mathrm{J}$ Med Internet Res 2010;12(1):e4 [FREE Full text] [doi: 10.2196/jmir.1376] [Medline: 20164043]

54. van Genugten L, Dusseldorp E, Webb TL, van Empelen EP. Which combinations of techniques and modes of delivery in internet-based interventions effectively change health behavior? A meta-analysis. J Med Internet Res 2016;18(6):e155 [FREE Full text] [doi: 10.2196/jmir.4218] [Medline: 27268104]

55. Glanz K, Bishop DB. The role of behavioral science theory in development and implementation of public health interventions. Annu Rev Public Health 2010 Mar;31:399-418. [doi: 10.1146/annurev.publhealth.012809.103604] [Medline: 20070207]

56. Michie S, van Stralen MM, West R. The behaviour change wheel: a new method for characterising and designing behaviour change interventions. Implement Sci 2011;6:42 [FREE Full text] [doi: 10.1186/1748-5908-6-42] [Medline: 21513547]

57. Subhi Y, Bube SH, Rolskov BS, Skou TAS, Konge L. Expert involvement and adherence to medical evidence in medical mobile phone apps: a systematic review. JMIR Mhealth Uhealth 2015 Jul 27;3(3):e79 [FREE Full text] [doi: 10.2196/mhealth.4169] [Medline: 26215371]

58. Pereira-Azevedo N, Osório L, Cavadas V, Fraga A, Carrasquinho E, Cardoso de Oliveira E, et al. Expert involvement predicts mHealth app downloads: multivariate regression analysis of urology apps. JMIR Mhealth Uhealth 2016;4(3):e86 [FREE Full text] [doi: 10.2196/mhealth.5738] [Medline: 27421338]

59. Martínez-Pérez B, de la Torre-Díez I, López-Coronado M. Mobile health applications for the most prevalent conditions by the World Health Organization: review and analysis. J Med Internet Res 2013;15(6):e120 [FREE Full text] [doi: 10.2196/jmir.2600] [Medline: 23770578]

60. Modave F, Bian J, Leavitt T, Bromwell J, Harris IC, Vincent H. Low quality of free coaching apps with respect to the American College of Sports Medicine guidelines: a review of current mobile apps. JMIR Mhealth Uhealth 2015;3(3):e77 [FREE Full text] [doi: 10.2196/mhealth.4669] [Medline: 26209109]

61. Mendiola MF, Kalnicki M, Lindenauer S. Valuable features in mobile health apps for patients and consumers: content analysis of apps and user ratings. JMIR Mhealth Uhealth 2015 May 13;3(2):e40 [FREE Full text] [doi: 10.2196/mhealth.4283] [Medline: 25972309]

62. Adjust. 2016. The Zombie Uprising: a look at the undead App Store in 2016 URL: https://www.adjust.com/resources/ insights/app-zombies-2016/ [accessed 2018-02-14] [WebCite Cache ID 6xEWc7zgL]

63. Yardley L, Spring BJ, Riper H, Morrison LG, Crane DH, Curtis K, et al. Understanding and promoting effective engagement with digital behavior change interventions. Am J Prev Med 2016 Nov;51(5):833-842. [doi: 10.1016/j.amepre.2016.06.015] [Medline: 27745683]

64. Girardello A, Michahelles F. AppAware: which mobile applications are hot? 2010 Sep Presented at: Proceedings of the 12th International Conference on Human Computer Interaction With Mobile Devices Services; 2010; Lisbon, Portugal. 
65. Kuehnhausen M, Frost VS. Trusting smartphone apps? To install or not to install, that is the question. 2013 Feb Presented at: 2013 IEEE International Multi-Disciplinary Conference on Cognitive Methods in Situation Awareness and Decision Support (CogSIMA); 2013; San Diego, CA, USA. [doi: 10.1109/CogSIMA.2013.6523820]

66. Gov.uk. Personalised health Care 2020: work stream 1.2 Roadmap. Enable me to make the right health and care choices. Providing citizens with access to an assessed set of NHS and social care 'apps' URL: https://www.gov.uk/government/ uploads/system/uploads/attachment data/file/433170/NIB WS 1 2.pdf [accessed 2017-09-25] [WebCite Cache ID 6tk3fDkZP]

\section{Abbreviations}

BCT: behavior change technique

mHealth: mobile health

NHS: National Health Service

PA: physical activity

PABAK: prevalence-adjusted bias-adjusted kappa

RCT: randomized controlled trial

SUS: System Usability Scale

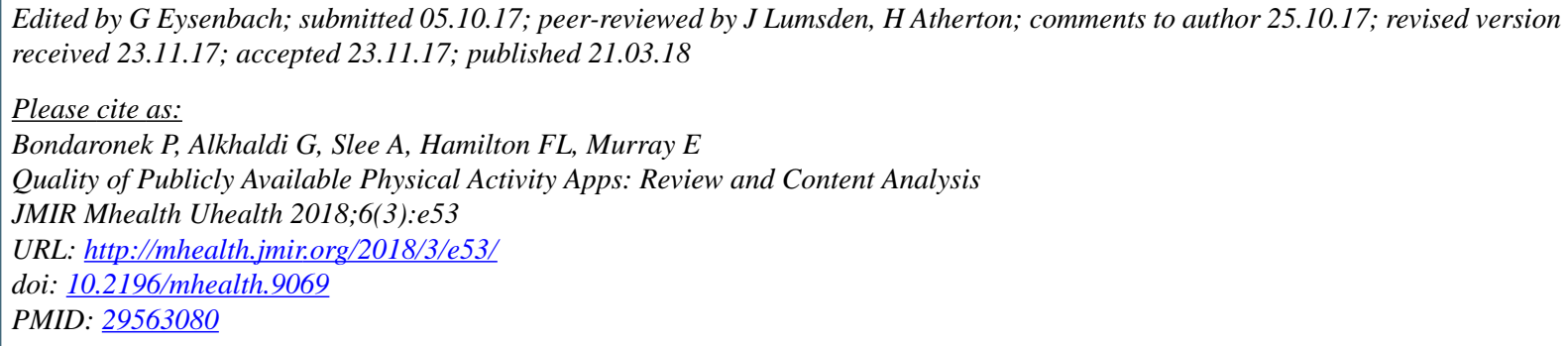

(CPaulina Bondaronek, Ghadah Alkhaldi, April Slee, Fiona L Hamilton, Elizabeth Murray. Originally published in JMIR Mhealth and Uhealth (http://mhealth.jmir.org), 21.03.2018. This is an open-access article distributed under the terms of the Creative Commons Attribution License (https://creativecommons.org/licenses/by/4.0/), which permits unrestricted use, distribution, and reproduction in any medium, provided the original work, first published in JMIR mhealth and uhealth, is properly cited. The complete bibliographic information, a link to the original publication on http://mhealth.jmir.org/, as well as this copyright and license information must be included. 